\title{
Nursing interventions for the early detection of ward patients' clinical deterioration: an integrative review
}

Intervenções de enfermagem na monitorização da deterioração clínica da pessoa em enfermaria hospitalar: uma revisão integrativa

Intervenciones de enfermería en la monitorización del deterioro clínico de la persona en enfermería hospitalaria: una revisión integradora

Catarina Moura Freitas*; Emídio Polónio Preto**; Carla Alexandra Fernandes Nascimento***

\begin{abstract}
Background: Clinical deterioration is sometimes mishandled in hospital wards resulting in increased likelihood of cardiorespiratory arrest, unplanned intensive care admissions, and death.

Objectives: To identify nursing interventions aimed at the early detection of the clinical deterioration of ward patients.

Methodology: Integrative literature review through the search for published and gray literature in CINAHL, MEDLINE, and ScienceDirect databases.

Results: A total of 534 documents were identified, of which 11 were selected for data extraction and analysis.

Conclusion: The monitoring of vital signs, either individually or in combination or to obtain an early warning score, is the most widely performed nursing intervention identified in the literature.
\end{abstract}

Keywords: clinical deterioration; nursing care; monitoring, physiologic; patient safety

\section{Resumo}

Enquadramento: A deterioração clínica da pessoa nem sempre é bem gerida em contexto de enfermaria resultando numa maior probabilidade de paragem cardiorrespiratória, internamentos náo programados em unidade de cuidados intensivos e aumento da mortalidade. Objetivos: Identificar intervençóes de enfermagem realizadas na deteção atempada da deterioração clínica da pessoa em contexto de enfermaria hospitalar.

Metodologia: Revisão integrativa da literatura, realizada através da pesquisa de trabalhos publicados e literatura cinzenta nas bases de dados CINAHL, MEDLINE e ScienceDirect.

Resultados: Identificaram-se 534 resultados, dos quais se selecionaram 11 documentos para análise e extração dos dados.

Conclusáo: A avaliação dos sinais vitais, quer de forma individual, quer de forma a obter uma avaliação em escalas de early warning score, são as intervençôes de enfermagem realizadas identificadas na literatura.

Palavras-chave: deterioração clínica; cuidados de enfermagem; monitorizaçáo fisiológica; segurança do paciente

*MSc., RN, Hospital of Santo Espírito da Ilha Terceira, 9700-042, Angra do Heroísmo, Portugal [catarinamfreitas@hotmail.com]. Contribution to the article: literature search; data collection, analysis, and discussion; article writing.

Address for correspondence: Rua Dr. João Costa n ${ }^{\circ} 11$, Santa Luzia, 9700-042, Angra do Heroísmo, Portugal.

Heroismo, Portugal.
$* *$ RN, Intensive Care Unit, Hospital of Santo Espírito da Ilha Terceira, 9700-042, Angra do Heroismo, Portugal [eppblack@hotmail.com]. Contribution to the article: data analysis and discussion; article writing.

***:Ph.D., Adjunct Professor, Medical-Surgical/Adult and Elderly Department, Lisbon School of Nursing, 1600-190, Lisboa, Portugal [carla.nascimento@esel.pt]. Contribution to the article: data analysis and discussion; article writing

\section{Resumen}

Marco contextual: El deterioro clínico de la persona no siempre se gestiona bien en el contexto de la enfermería, lo que da como resultado una mayor probabilidad de parada cardiorrespiratoria, internamientos no programados en la unidad de cuidados intensivos y un aumento de la mortalidad.

Objetivos: Identificar las intervenciones de enfermería realizadas en la detección temprana del deterioro clínico de la persona en el contexto de la enfermería hospitalaria.

Metodología: Revisión integradora de la literatura, realizada a través de la investigación de trabajos publicados y literatura gris en las bases de datos CINAHL, MEDLINE y ScienceDirect.

Resultados: Se identificaron 534 resultados, de los cuales se seleccionaron 11 documentos para analizarlos y extraer los datos.

Conclusión: La evaluación de los signos vitales, tanto de forma individual, como para obtener una evaluación en escalas de early warning score, son las intervenciones de enfermería realizadas identificadas en la literatura.

Palabras clave: deterioro clínico; atención de enfermería; monitoreo fisiológico; seguridad del paciente 


\section{Introduction}

Patient safety has been the target of growing concern worldwide, as it is a fundamental principle in health care which has a significant impact on care quality (Edwards, 2005). Therefore, the National Patient Safety Agency (2007) considers that the early detection of clinical deterioration is essential to reduce mortality rates associated with cardiopulmonary arrest (CPA).

Today, hospitalized patients tend to have more complex clinical situations and a higher number of comorbidities, which increases the likelihood of clinical deterioration during hospitalization (Preece, Hill, Horswill, \& Watson, 2012). In this way, it is possible to infer that ward patients might be in a situation similar to those who are in intensive care units (ICUs), which puts them at risk of experiencing an adverse event such as a cardiac and/or cardiopulmonary arrest.

Regardless of the underlying process, the signs of acute illness are similar because they reflect changes in the respiratory, cardiac, and neurological systems. Physiological alterations, in one or more parameters, are associated with a higher likelihood of CPA, unplanned ICU admissions, and death (Soar et al., 2015). Within this scope, the European Resuscitation Council guidelines suggest a CPA prevention approach focused on the chain of prevention, staff training/ education, monitoring and identification of deterioration, and a system that allows asking for help and getting an effective response (Soar et al., 2015). Similarly, the American Heart Association for Cardiopulmonary Resuscitation and Emergency Cardiovascular Care guidelines (Kronick et al., 2015) recommend the existence of an in-hospital chain of survival. The first link in this chain depends on an appropriate surveillance system to prevent CPA. If CPA occurs, health institutions should have a system that allows the notification and intervention of a multidisciplinary team specialized in caring for these critically ill patients.

Considering these aspects as a way to facilitate the early detection of clinical deterioration, Rapid Response Systems (RRSs) have been implemented to allow for its recogni- tion in health institutions and subsequent intervention (Joshi, Campbell, Gooch, Anstey, \& Landy, 2015). RRSs are aimed at identifying the clinical condition of the ward patient in the minutes immediately before CPA to check if something can be done to prevent clinical deterioration and subsequent ICU admission (Winters \& DeVita, 2015). According to the authors, RRSs are based on the early recognition of the clinical deterioration of the ward patient, thus contributing to the intervention of a multidisciplinary critical care team. Its main objective is to reduce the occurrence of CPA, thus reducing mortality rates and the need for unplanned ICU admissions. According to the authors, nurses often put RRSs into motion when they recognize the clinical deterioration of the ward patient. According to Benner (2001), the diagnostic and patient-monitoring function is a nursing intervention that contributes to the promotion of patient safety because it allows for the early detection of clinical deterioration situations. However, it should be noted that aspects such as work overload resulting from the complexity and increased demands of caring for critically-ill patients and the lack of differentiated and experienced staff to support decision-making contribute to the difficulties in the early identification of ward patients' clinical deterioration (National $\mathrm{Pa}$ tient Safety Agency, 2007).

The literature suggests that the majority of adverse events that occur in health care settings result from ineffective communication and situations of misunderstanding within the team, reducing patient safety (Courtenay, Nancarrow, \& Dawson, 2013).

In summary, it is more difficult today to detect and intervene in a situation of clinical deterioration in ward patients. Therefore, the objective of this integrative literature review (ILR) was to identify the nursing interventions aimed at the early detection of ward patients' clinical deterioration.

\section{Methodological procedures of integrative review}

To meet the objective set out, the ILR was 
conducted according to the Joanna Briggs Institute guidelines (Joanna Briggs Institute [JBI], 2015), based on a research question designed using the PCC (Population, Concept, and Context) strategy: Which nursing interventions promote the safety of the patient at risk for clinical deterioration in a ward?

The inclusion and exclusion criteria of studies were defined based on the popu- lation, context, language, date of publication, and nursing intervention for detection of deterioration (Table 1). The population was composed of adults aged 18 to 65 years. An initial search showed a study published in 2005 on nursing interventions for the detection of clinical deterioration; for this reason, this date was established as the minimum date possible for inclusion.

Table 1

Inclusion and exclusion criteria

\begin{tabular}{|c|c|c|}
\hline & Inclusion criteria & Exclusion criteria \\
\hline Population & Adults ( 18 to 65 years) & Pregnant women and pediatric population \\
\hline Context & Hospital ward & $\begin{array}{l}\text { Psychiatric and obstetric wards, ICU, emergency } \\
\text { and pre-hospital units }\end{array}$ \\
\hline Language & Portuguese and English & Other languages than those selected \\
\hline $\begin{array}{l}\text { Date of } \\
\text { publication }\end{array}$ & 1 January 2005 to 30 June 2016 & Studies published before 2005 \\
\hline Intervention & $\begin{array}{l}\text { Nursing interventions for the early detection of } \\
\text { clinical deterioration }\end{array}$ & $\begin{array}{l}\text { Interventions performed by nursing students and/or } \\
\text { other nursing categories that do not exist in Portugal }\end{array}$ \\
\hline
\end{tabular}

First, searches in conventional online databases were performed to identify the most relevant articles on the topic under analysis and the keywords and search terms to be used. The search was conducted in the CINAHL, MEDLINE, and ScienceDirect databases between May and July 2016. Two studies found in additional searches were also included because they met the inclusion criteria. Initially, a natural language search was conducted in the databases using the terms identified in the keywords of the articles found in the initial search. Then, descriptors/medical subject headings $(\mathrm{MeSH})$ and major headings $(\mathrm{MH})$ were combined using the Boolean operators "OR" and "AND", while considering the expression "deteriorating patient" in the full text. The search strategy used in CINAHL was as follows: (MH "Nursing Interventions") OR (MH "Nursing Process") OR (MH "Nursing Protocols") OR (MH "Nursing Care Plans") OR (MH "Patient Assessment") OR (MH "Monitoring, Physiologic") AND (MH "Early Intervention") OR "Rapid response system" OR "Deteriorating patient"; in MEDLINE: (MH "Nursing") OR (MH "Nursing Process") OR (MH "Nursing Assessment") OR ( $\mathrm{MH}$ "Patient Care Planning”) OR (MH “Monitoring, Physiologic") AND (MH "Hospital Rapid response team") OR "Deteriorating patient"; and in ScienceDirect: "Nursing intervention" and "deteriorating patient", activating the filters for date of publication and full text. Quantitative and qualitative primary studies were included, as well as systematic literature reviews, without restrictions on sample size. However, only articles with full text available and which were not opinion articles were included. The free search and the search on the databases retrieved 534 articles. Of these, 15 articles were removed for being duplicates. The process of article identification and selection is shown in Figure 1, and is structured as follows: 1) Critical and reflective reading of titles and summaries with the purpose of checking if they met the inclusion criteria; 2) Full-text reading of the articles and their division according to the inclusion criteria, having obtained 11 articles for data extraction and analysis. 


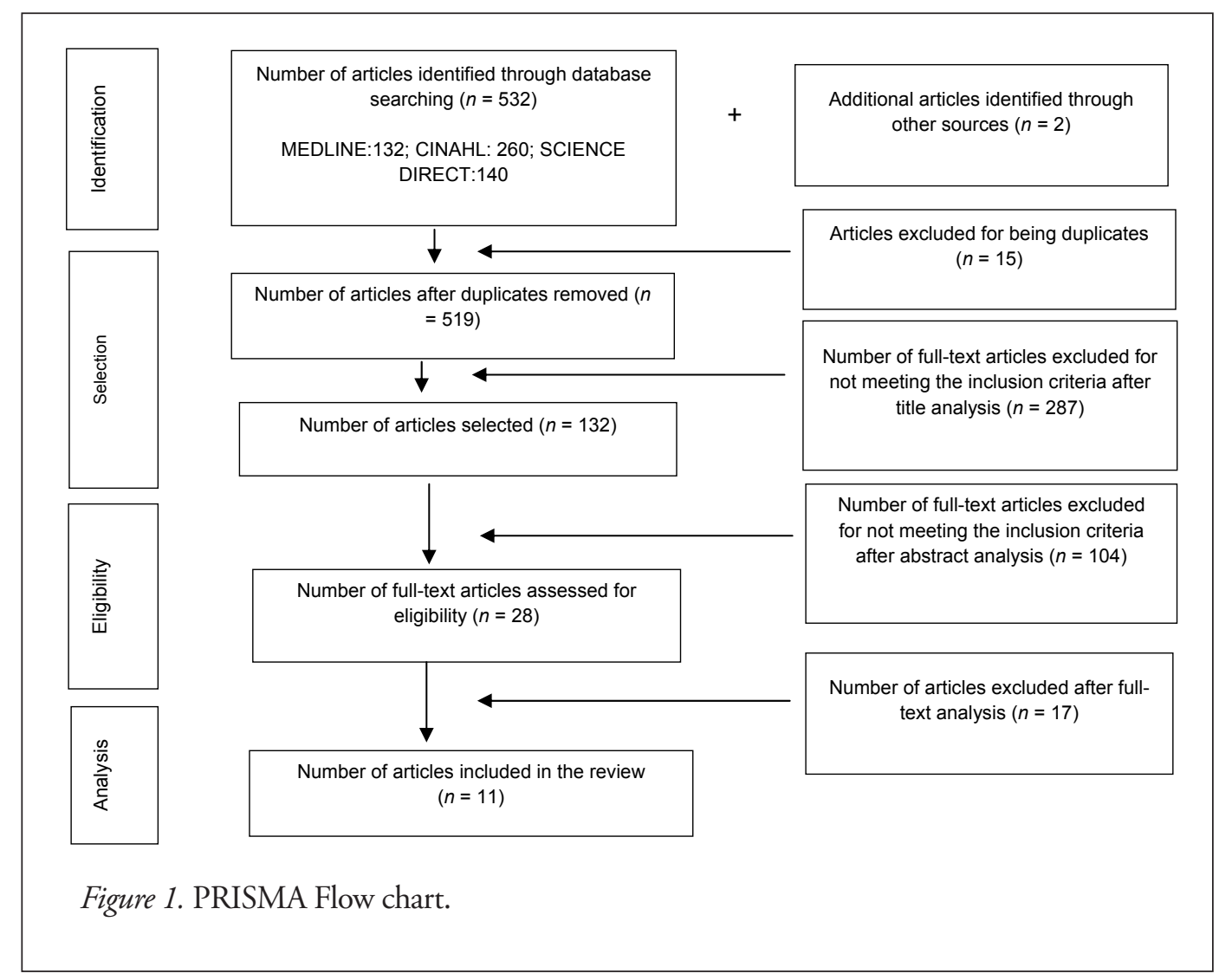

The process of evaluating the methodological quality of the articles was conducted independently by two reviewers using the JBI - Meta Analysis of Statistics Assessment and Review Instrument (MAStARI) critical appraisal tools and the JBI - Qualitative Assessment and Review Instrument critical appraisal tool for studies of quantitative and qualitative, respectively. The information was extracted and synthetized from quantitative and qualitative studies using the JBI-MAStARI and JBI QARI Critical Appraisal Checklist for Interpretive \& Critical Research data extraction tools, respectively. Table 2 includes data on the publication itself and the methodology used: type of study, study objective, main findings, and identified nursing interventions.

\section{Results and interpretation}

The monitoring and recording of vital signs are essential nursing interventions for the early detection of clinical deterioration. This is often confirmed by the monitoring of vital parameters such as respiratory rate, heart rate, and blood pressure (Andrews \& Waterman, 2005; Liaw, Scherpbier, Klainin-Yobas, \& Rethans, 2011). However, authors such as Andrews and Waterman (2005) and Odell (2015) have reported gaps in nurses' interventions to conduct a complete monitoring of vital signs and, although this is a key nursing intervention, the evidence on monitoring is scarce.

According to Aneman (2010), the predicting signs of clinical instability are present several hours before clinical deterioration, regardless of progression to cardiac or cardiopulmonary arrest, which could enable a timely intervention. In this review, all studies have identified the monitoring of vital signs as a nursing intervention, whether performed in isolation or combined, that enables the calculation of an Early Warning Score (EWS). According to Benner (2001), an experienced nurse is able to identify the patient's clin- 
ical deterioration before explicit alterations in vital signs by providing an early warning signal; however, nurses recognize the need to confirm these findings. Therefore, in both literature reviews (S2 and S5), nurses' intuition and use of subjective data emerge as a way of recognizing the patient's clinical deterioration and only after these will the nurses assess the vital signs to confirm their findings.

Since physiological variables are often interrelated by compensatory mechanisms, heart rate, respiratory rate, blood pressure, level of consciousness, pulse oximetry, and urine output should be fully assessed and documented (Aneman, 2010; Smith \& Prytherch, 2011).

Vital signs are currently assessed using electronic equipment, but there is evidence that, outside ICUs, respiratory rate is assessed through observation, leading to insufficient, subjective, and unreliable results (Smith \& Prytherch, 2011). S4, S5, S6, and S9 are in line with this idea, indicating that observation, touch, and hearing are used as monitoring methods by assessing the patient's skin color, temperature, and respiratory pattern (depth and sounds).

According to Osborne, Douglas, Reid, Jones, and Gardner (2015), although clinical deterioration requires other nursing interventions beyond the monitoring of vital signs, this was the most widely used nursing intervention. The authors believe that this finding is associated with the current focus on parameters specified by the RRSs, which could lead nurses to undervalue the performance of a more comprehensive patient assessment. If performed, this comprehensive assessment could allow for the early detection of subtle changes in the patient's health status. In line with this, Kyriacos, Jelsma, James, and Jordan (2014) underline that it is not enough to assess and record vital signs because the patient's safety continues to rely on the nurses' clinical judgment. According to Tanner (2006), clinical judgment in nursing requires "an understanding of not only the pathophysiological and diagnostic aspects of a patient's clinical presentation and disease, but also the illness experience for both the patient and family and their physical, social, and emotional strengths and coping resources" (p. 205).

The purpose of the EWS is to provide an accessible and systematic way to assess the patients' health status and guide the response in case of a situation of clinical deterioration, based on a scoring system of physiological measures obtained at the time of admission or in regular monitoring moments during hospitalization (Capan, Ivy, Rohleder, Hickman, \& Huddleston, 2015). Since its introduction in health institutions, EWSs have been updated and modified. Examples are the Modified Early Warning Score (MEWS) and the National Early Warning Score (NEWS; Kyriacos et al., 2014). In the same way as the initial EWS, these scales result from the monitoring of five physiological parameters: heart rate, respiratory rate, systolic blood pressure, temperature, and level of consciousness. In addition, the NEWS includes peripheral oxygen saturation and supplemental oxygen, and, in some institutions, the MEWS includes peripheral oxygen saturation, urine output, blood glucose and/or analytical levels, and pain. These parameters, although they are not part of the scale, are considered in situations of clinical deterioration (Kyriacos et al., 2014). Taking into account that alterations in heart rate, respiratory rate, blood pressure, and level of consciousness are indicators of physiological deterioration, a combined monitoring of these parameters is expected to have a higher predictive value than an isolated monitoring (Smith \& Prytherch, 2011).

As already mentioned, vital signs were assessed in order to group values and obtain a EWS. In this way, the calculation of the MEWS to detect clinical deterioration was also one of the nursing interventions identified in 8 of the 11 reviewed studies (S1, S3, S4, S5, S6, S7, S8, and S11). As with nurses' intuition and use of subjective data, which are confirmed by the monitoring of vital signs, S4 also found that the MEWS was only calculated to confirm the situation of clinical deterioration rather than to detect it. The sum of the points assigned to each parameter results in the EWS, which is used to increase the frequency of monitoring of vital signs, request the collaboration of more 
experienced professionals, or call the rapid response team (RRT) (Smith \& Prytherch, 2011). The request for differentiated help and the activation of an RRT seem to be the nursing interventions used to respond to the identified situation of clinical deterioration (S3, S4, S5, S6, S7, S8, and S11).

The MEWS was considered to be an effective instrument of communication of the clinical deterioration to the physician since it allows systematizing findings and presenting them in an objective manner (S1, S3, S5, S7, and S11). Although three studies (S3, S6, and S7) mentioned the use of the Situation, Background, Assessment, Recommendation (SBAR) communication tool to convey information, different results were obtained. S7 concluded that, after the introduction of this tool in a hospi- tal, nurses' perceptions of the effectiveness of communication and collaboration within the multidisciplinary team increased, the number of unplanned ICU admissions increased, and the number of unexpected deaths decreased. However, S6 showed that SBAR was used by only one out of 47 nurses with training to use it. In turn, in S3, this tool is considered to be an effective strategy to increase the number of nurses' clinical observations.

In view of the above, as stated by Mitchell et al. (2010) it is possible to say that a timely intervention to prevent or stop the progression of clinical deterioration requires a set of interventions that includes the monitoring and interpretation of vital signs, followed by an effective communication and adequate clinical response.

Table 2.

Synthesis of the evidence found

\begin{tabular}{|c|c|c|c|c|}
\hline Study identification & Method & Study objective & Main findings & $\begin{array}{l}\text { Identified nursing } \\
\text { interventions }\end{array}$ \\
\hline $\begin{array}{l}\text { S1 - Andrews, T., \& } \\
\text { Waterman, H. (2005). } \\
\text { Packaging: A grounded } \\
\text { theory of how to report } \\
\text { physiological deteriora- } \\
\text { tion effectively. Journal } \\
\text { of Advanced Nursing, } \\
52(5), 473-481 . \\
\text { doi:10.1111/j.1365- } \\
2648.2005 .03615 . x\end{array}$ & $\begin{array}{l}\text { Qual- } \\
\text { itative } \\
\text { study. }\end{array}$ & $\begin{array}{l}\text { To identify how } \\
\text { ward staff uses vital } \\
\text { signs and the EWS } \\
\text { to package physi- } \\
\text { ological deteriora- } \\
\text { tion effectively to } \\
\text { facilitate referral to } \\
\text { doctors. }\end{array}$ & $\begin{array}{l}\text { Participants reported that quanti- } \\
\text { fiable evidence is the most effec- } \\
\text { tive means of referring patients to } \\
\text { doctors, and the Early Warning } \\
\text { Score achieves this by improving } \\
\text { communication among profes- } \\
\text { sionals. Rather than reporting } \\
\text { changes in individual vital signs, } \\
\text { the EWS effectively packages } \\
\text { them together. It gives nurses a } \\
\text { precise, concise and unambig- } \\
\text { uous means of communicating } \\
\text { deterioration, and confidence in } \\
\text { using medical language. }\end{array}$ & $\begin{array}{l}\text { Monitoring of vital } \\
\text { signs and calcula- } \\
\text { tion of the EWS so } \\
\text { as to package the } \\
\text { values together. }\end{array}$ \\
\hline
\end{tabular}

S2 - Odell, M., Victor, C., \& Oliver, D. (2009). Nurses' role in detecting deterioration in ward patients: Systematic literature review. Journal of Advanced Nursing, 65(10), 1992-2006. doi:10.1111/j.13652648.2009.05109.x
Findings were grouped into four main themes: recognition; recording and reviewing; reporting; and responding and rescuing. Findings suggest that intuition plays an important role in the de- Intuition, validated tection of clinical deterioration, by assessment of and vital signs are used to validate vital signs. intuitive feelings. The process is complex and influenced by many factors, including nurses' experience and education and their relationship with the team. 
S3 - Mitchell, I. A., McKay, H., Van Leuvan, C., Berry, R., McCutcheon, C., Avard, B., ... Lamberth, P. (2010). A prospective controlled trial of the effect of a multi-faceted intervention on early recognition and intervention in deteriorating hospital patients. Resuscitation, 81(6), 658-666.doi:10.1016/j. resuscitation.2010.03.001
To determine whether the introduction of a multi-faceted intervention (track and trigger system and an education program, COMPASS(C) to detect clinical deterioration would decrease the rate of predetermined adverse outcomes.
The introduction of a multi-faceted intervention in the ward to detect clinical deterioration may benefit patients through the increased monitoring of vital signs and triggering of a medical review following an episode of clinical instability.
Monitoring of vital signs, calculation of the MEWS, activate/notify the medical response.
S4 - Donohue, L. A., \& Endacott, R. (2010).

Track, trigger and teamwork: Communication of deterioration in acute medical and surgical wards. Intensive and Critical Care Nursing, 26(1), 10-17 doi:10.1016/j. iccn.2009.10.006.
To examine the perceptions of ward

Qualand RRT nurses itative about the managestudy. ment of ward patients with clinical deterioration.
Nurses detected clinical deterioration when assessing their patients visually, looking for recurring signs and symptoms, and comparing their evolution over time. Although the EWS was not a key component of patient assessment, it was frequently used to quantify deterioration when any changes were detected.
Visual assessment of the patient;

Calculation of the EWS.
S5 - Liaw, S. Y., Scherpbier, A., Klainin-Yobas, P., \& Rethans, J. J. (2011). A review of educational strategies to improve nurses' roles in recognizing and responding to deteriorating patients. International Nursing Review, 58(3), 296-303. doi:10.1111/j.14667657.2011.00915.x
Literature review, between 2000 and 2010 .

S6 - Ludikhuize, J., de Jonge, E., \& Goossens, A. (2011). Measuring adherence among nurses one year after training in applying the Modified Early Warning Score and Situation-Background-Assessment-Recommendation instruments. Resuscitation,782(11), 14281433. doi:10.1016/j.resuscitation.2011.05.026
To identify nurses' educational needs and explore educational strategies to enhance their ability to recognize and intervene in cases of clinical deterioration in wards.
Findings identified the educational need to empower nurses to recognize and intervene in patient deterioration. The review of educational programmes and their outcomes identified information and strategies in deprived areas.
Intuition;

Monitoring of vital signs.

Use of subjective data (observation, touch, and hearing).

Calculation of the EWS.
Of the trained nurses, $77 \%$ versus $58 \%$ of the non-trained group assessed the patient immediately. On subsequent assessment, respiratory rate was measured twice as frequently. No differences were found in the measurement of other vital parameters. The MEWS was determined by $11 \%$ of trained nurses. Subsequent notification of the physician was performed by $67 \%$ of the trained versus $43 \%$ of the non-trained nurses. The SBAR communication tool was used by only one nurse. Trained nurses are able to identify a deteriorating patient and react more appropriately.
Monitoring of vital signs; activate/notify the medical response. recognizing clinical deterioration 
S7 - De Meester, K., Verspuy, M., Monsieurs, K. G., \& Van Bogaert, P. (2013). SBAR improves nurse-physician communication and reduces unexpected death: A pre and post intervention study. Resuscitation, 84(9), 1192-1196. doi:10.1016/j.resuscitation.2013.03.016
To determine how the use of SBAR can improve the perception of an effective nurse-physician communication and collaboration in serious adverse events in hospital wards.
The introduction of the SBAR communication tool increased nurses' perception of effective communication and collaboration. Nurses were better prepared to contact and communicate changes to a physician by using SBAR items. The number of unplanned ICU admissions increased in the post-intervention period and the number of unexpected deaths decreased. The number of RRT calls remained unchanged. These results seem to indicate that the introduction of SBAR allows for the early detection and response in case of clinical deterioration.
Patient (Airway; Breathing and ventilation; Circulation; Disability; Exposure/ environmental control - ABCDE) assessment; Calculation of the EWS (MEWS); Communication with the physician (through SBAR).
S8 - Ludikhuize, J.,

Borgert, M., Binnekade, J., Subbe, C., Dongelmans, D., \& Goossens, A. (2014). Standardized measurement of the Modified Early Warning Score results in enhanced implementation of a Rapid Response System: A quasi-experimental study. Resuscitation, 85(5), 676-682. doi: $10.1016 /$ j.resuscitation.2014.02.009
To study the effect

Quantitative, randomized, quasi-experimental study. of the assessment protocol (three times per day) of the MEWS versus assessment per clinical indication on the activation of the RRS.
The calculation of the MEWS based on vital signs occurred in $70 \%$ on the wards with protocol versus $2 \%$ in the control group. Compliance with the protocol was present in $68 \%$ of the assessments versus $4 \%$ in the control group. There were 90 calls to primary physicians on the wards with protocol and 9 calls on the control wards. On wards with protocol, there were twice as much RRT calls. The monitoring of vital signs and calculation of the MEWS, three times per day, results in the improved detection of physiological abnormalities and more reliable activations of the RRT.
Monitoring of vital signs; Calculation of the EWS (MEWS); Activation of the RRT.

\section{S9 - Osborne, S.,}

Douglas, C., Reid, C., Jones, L., \& Gardner, G. (2015). The primacy of vital signs - Acute care nurses' and midwives' use of physical assessment skills: A cross sectional study. International Journal of Nursing Studies, 52(5), 951962. doi:10.1016/j. jnurstu.2015.01.014
Skills used by most nurses in clinical practice included the monitoring of temperature, oxygen saturation, blood pressure, breathing effort, skin, wounds, and mental status. Reliance on others and technology (35.77\%), lack of confidence (5.52\%), work area $(3.79 \%)$, and clinical role (44.24\%) are significant predictors of the extent of physical assessment skill use. Patients' increasing acuity requires more than the monitoring of vital signs; however, it is nurses' main intervention when assessing the patient.
Monitoring of vital signs (including assessment of mental status, skin, and wounds). 
S10 - Fasolino, T., \&

Verdin, T. 15). Nurs-

ing Surveillance and

Physiological Signs of

Deterioration. Med-

surg Nursing: Official

Journal of the Academy

of Medical-Surgical

Nurses, 24(6), 397-402.

Retrieved from http://

web.a .ebscohost.com.

ez-jmk. statsbiblioteket.

dk:2048/ehost/pd-

fviewer/pdfviewer?sid=-

ca11ab2c-ad1d-4249-

ad3a-a7963c497679@

session-

mgr4005\&vid $=1 \&$ hid $=$

4212\%5Cnhttp://

www.ncbi.nlm.nih.gov/

pubmed/26863702
This study found records of multiple physiological measurements of systolic and diastolic blood pressure, heart and respiratory rate, and $\mathrm{SpO}^{2}$ within regular intervals for medical-surgical patients. However, there is no record of mental status assessment and urine output was only recorded a few times. Specific components of nursing surveillance that permit recognition of patient clinical deterioration remained unclear.
Monitoring of vital signs (blood pressure, heart rate, respiratory rate, $\mathrm{SpO}^{2}$ ).
S11 - Stafseth, S. K., Grønbeck, S., Lien, T., Randen, I., \& Lerdal, A. (2016). The experiences of nurses implementing the Modified Early Warning Score and a 24-hour on-call Mobile Intensive Care Nurse: An exploratory study. Intensive and Critical Care Nursing, 34, 33-41. doi: 10.1016/j. iccn.2015.07.008
Three themes emerged: 1 ) experiences with the early recognition of deterioration using the MEWS, 2) collaboration and knowledge transfer between nurses, and 3) a new precise language used to communicate with physicians. The use of the EWS and support were perceived as improving care for deteriorating patients and for supporting the collaboration between professionals.
Calculation of the

EWS;

Activation of a more differentiated response (ICU nurse and/or RRT).

\section{Conclusion}

This ILR aimed to identify the nursing interventions used for the early detection of hospital ward patients' clinical deterioration. The 11 articles analyzed in this review show that the monitoring of vital signs, either individually or in combination to obtain a EWS, is the most widely used nursing intervention. They also highlight the importance of intuition and use of subjective data in patient assessment and aspects such as the communication of clinical deterioration and the activation of the RRT/ assistant physician as a result of these interventions.

This study has some limitations: it only included articles available through open access in the databases searched; three of the studies used qualitative methods and their results cannot be generalized; and only articles written in English were analyzed.

We believe that training in areas such as patient physical assessment and team communication are a significant contribution to achieve effective nursing interventions in this area. This training, combined with the use of the best scientific evidence available, will allow for a substantiated clinical judgment and decision-making.

Evidence on this topic is scarce, so we suggest that studies should be conducted on nursing interventions for the early detection of clinical deterioration. In addition, it would be equally important to analyze the results of the implementation of RRSs in health institutions, since they have a recognized impact on reducing mortality rates and unplanned ICU admissions, thus contributing to patient safety and leading to health gains in society in general. 


\section{References}

Andrews, T., \& Waterman, H. (2005). Packaging: A grounded theory of how to report physiological deterioration effectively. Journal of Advanced Nursing, 52(5), 473-481. doi: 10.1111/j.13652648.2005.03615.x.

Aneman, A. (2010). The rapid response system (management, organisation). In H. Flaatten, R. P. Moreno, C. Putensen, \& A. Rhodes (Eds.), Organisation and management of intensive care (pp. 41-52). Berlin, Deutschland: MWV Medizinish Wissenschaftliche Verlagsgesellscaft mbH \& Co. KG.

Benner, P. (2001). De iniciado a perito: Excelência e poder na prática clínica de enfermagem. Coimbra, Portugal: Quarteto.

Capan, M., Ivy, J. S., Rohleder, T., Hickman, J., \& Huddleston, J. M. (2015). Individualizing and optimizing the use of early warning scores in acute medical care for deteriorating hospitalized patients. Resuscitation, 93, 107-112. doi:10.1016/j.resuscitation.2014.12.032.

Courtenay, M., Nancarrow, S., \& Dawson, D. (2013). Interprofessional teamwork in the trauma setting: $\mathrm{A}$ scoping review. Human Resources for Health, 11(1), 57. doi: 10.1186/1478-4491-11-57.

Edwards, I.R. (2005). WHO World Alliance for patient safety. Drug Safety, 28(5), 379-386. Geneva. doi: 10.2165/00002018-200528050-00002.

Joshi, K., Campbell, V., Gooch, R., Anstey, C., \& Landy, M. (2015). Adult deterioration detection system (Q-Adds) based rapid response system (Rrs) reduces severity of illness and length of stay of Icu admissions from the ward in a regional hospital. Intensive Care Medicine Experimental, 3(Suppl 1), A141. doi: 10.1186/2197-425X-3-S1-A141.

Kronick, S. L., Kurz, M. C., Lin, S., Edelson, D. P., Berg, R. A., Billi, J. E., ... Welsford, M. (2015). Part 4: Systems of care and continuous quality improvement. Circulation, 132(18 suppl 2), S397-S413. doi: 10.1161/CIR.0000000000000258.

Kyriacos, U., Jelsma, J., James, M., \& Jordan, S. (2014). Monitoring vital signs: Development of a modified early warning scoring (Mews) system for general wards in a developing country. PLoS ONE, 9(1). doi: 10.1371/journal.pone.0087073

Liaw, S. Y., Scherpbier, A., Klainin-Yobas, P., \& Rethans, J. J. (2011). A review of educational strategies to improve nurses' roles in recognizing and responding to deteriorating patients. International Nursing Review, 58(3), 296-303. doi: 10.1111/j.1466-7657.2011.00915.x.

Mitchell, I. A., McKay, H., Van Leuvan, C., Berry,
R., McCutcheon, C., Avard, B., ... Lamberth, P. (2010). A prospective controlled trial of the effect of a multi-faceted intervention on early recognition and intervention in deteriorating hospital patients. Resuscitation, 81(6), 658-666. doi: 10.1016/j.resuscitation.2010.03.001.

National Patient Safety Agency. (2007). Recognising and responding appropriately to early signs of deterioration in hospitalised patients. London, England: NHS. Retrieved from http://www.nrls.npsa.nhs.uk/EasySiteWeb/getresource.axd?AssetID=60151.

Odell, M. (2015). Detection and management of the deteriorating ward patient: An evaluation of nursing practice. Journal of Clinical Nursing, 24(1-2), 173182. doi: 10.1111/jocn.12655.

Osborne, S., Douglas, C., Reid, C., Jones, L., \& Gardner, G. (2015). The primacy of vital signs - Acute care nurses' and midwives' use of physical assessment skills: A cross sectional study. International Journal of Nursing Studies, 52(5), 951-962. doi: 10.1016/j. ijnurstu.2015.01.014.

Preece, M. H., Hill, A., Horswill, M. S., \& Watson, M. O. (2012). Supporting the detection of patient deterioration: Observation chart design affects the recognition of abnormal vital signs. Resuscitation, 83(9), 1111-8. doi:10.1016/j.resuscitation.2012.02.009.

Smith, G. B., \& Prytherch, D. R. (2011). An overview of the afferent limb. In M. DeVita, K. Hillman, \& R. Bellomo (Eds.), Textbook of rapid response systems: Concept and implementation (pp. 177-188). London, England: Springer. doi: 10.1007/978-0-387-928531.

Soar, J., Nolan, J. P., Böttiger, B. W., Perkins, G. D., Lott, C., Carli, P., ... Deakin, C. D. (2015). European resuscitation council guidelines for resuscitation 2015. Resuscitation, 95, 100-147. doi: 10.1016/j.resuscitation.2015.07.016.

Tanner, C. A. (2006). Thinking like a nurse: A research-based model of clinical judgment in nursing. The Journal of Nursing Education, 45(6), 204-211. Retrieved from http://www.mccc.edu/nursing/documents/Thinking_Like_A_Nurse_Tanner.pdf.

The Joanna Briggs Institute. (2015). The Joanna Briggs Institute reviewers' manual 2015: methodology for JBI scoping reviews, 1-24. Retrieved from http://joannabriggs.org/assets/docs/sumari/ReviewersManual_Mixed-Methods-Review-Methods-2014-ch1.pdf.

Winters, B. D., \& DeVita, M. (2015). Rapid response systems history and terminology. In M. A. DeVita, K. Hillman, \& R. Bellomo (Eds.), Textbook of rapid response systems: Concept and Implementation (Vol. 1). Springer. doi: 10.1017/CBO9781107415324.004. 